where ozone depletion is threatened is thus determined by the spatial extent of the volcanic cloud and can be far more extensive. For example, the volume of atmosphere between the equator and $50^{\circ} \mathrm{N}$ (the approximate bounds of the $\mathrm{El}$ Chichon cloud) is more than an order of magnitude greater than that within the polar vortex, say poleward of $70^{\circ} \mathrm{N}$. If reactions on volcanic aerosol perturb the partitioning of the nitrogen and chlorine species over such a volume, the effect on the global quantities of ozone could be considerable.

The stratospheric sulphate aerosol layer was discovered $^{12}$ in the early 1960 s. In 'normal' conditions, that is in the absence of perturbation by volcanic effects, sulphur compounds reside in the stratosphere, largely in the form of sulphur dioxide and carbonyl sulphide, with mixing ratios in the range $0.1-1.0$ parts per $10^{9}$ by volume. Both are converted photochemically to sulphuric acid vapour. Under suitable conditions, aqueous sulphuric acid droplets form on existing condensation nuclei. Once formed, the particles can grow by condensation of sulphuric acid and water vapour, and by the coagulation of particles ${ }^{13}$.

Larger particles can be removed by sedimentation, and at upper altitudes (above approximately $30 \mathrm{~km}$ ) particles evaporate. The result is the formation of a layer of particles in the low stratosphere with a distinct maximum $5-7 \mathrm{~km}$ above the tropopause. The normal background concentration of aerosol particles is of the order of 10 per milligram of air, and the available surface area of the order of $1 \mu^{2} \mathrm{~cm}^{-3}$. But in the aftermath of volcanic eruptions, both may be increased by several orders of magnitude.

Following El Chichon, some $3-8 \times 10^{12} \mathrm{~g}$ of sulphur dioxide were injected into the stratosphere $^{14,15}$. On the basis of their measurements, Hofmann and Solomon point out that this increased the surface area available for chemical reactions from $0.75 \mu \mathrm{m}^{2} \mathrm{~cm}^{-3}$ to $20-50 \mu \mathrm{m}^{2} \mathrm{~cm}^{-3}$. The latter, they point out, is comparable to that observed in polar regions, which is associated with clouds of nitric acid trihydrate. They conclude using measured (or in one case an assumed) heterogeneous reaction rates on sulphuric acid surfaces, that ozone concentrations were reduced by up to 15 per cent over a substantial portion of the Northern Hemisphere. If this decline is representative of that at other altitudes where cloud particles exist (up to $28 \mathrm{~km}$; ref. 16), the net atmospheric ozone reduction would be at least comparable to that observed during the formation of the Antarctic ozone hole.

As the authors state, their results depend critically on their choice of accommodation coefficients, factors which control the rate of heterogeneous conversion of chlorine and nitrogen compounds on particle surfaces. These are clearly uncertain. By perhaps their choice of the $\mathrm{N}_{2} \mathrm{O}_{5}+\mathrm{HCl}$ reaction rate on sulphuric acid surfaces, they have tended to maximize their ozone loss. It would be instructive to examine whether the $\mathrm{ClO}$ mixing ratios implied by their choice can be confirmed by direct measurement.

Although the authors suggest that the consequences of massive volcanic injection can be very significant, the impact of background aerosol levels are apparently less marked ${ }^{17}$. However, it is intriguing that, when the effects of El Chichon aerosol are included, Hofmann and Solomon's modelled latitude gradient of nitric acid reproduces the gradient observed by the LIMS instrument (their Fig. 10) in January 1979 , a period of much lower stratospheric aerosol concentration. Without heterogeneous effects, the 1979 observations and model calculations differ by a factor of two.

At high latitudes, heterogeneous production of nitric acid on nitric acid trihydrate particles is likely to have occurred during the cold late December and early January. However, the agreement at low latitudes implies at face value that the heterogeneous effects on the partitioning of reactive nitrogen compounds, even on background aerosol, can be large. The effect of background aerosol concentrations on the partitioning of the chlorine species may thus be large also. This would enhance the ozone loss reported by earlier studies ${ }^{17}$ which did not include the reaction of $\mathrm{HCl}$ with $\mathrm{N}_{2} \mathrm{O}_{5}$.

As Hofmann and Solomon point out, rather than being interpreted as definitive, their results should be regarded as illustrative of possible effects. With increasing atmospheric chlorine concentrations, these possible effects should give serious cause for concern, particularly given uncertainties in heterogeneous reaction rates.

R. L. Jones is at the Meteorological Office, London Road, Bracknell RG12 2SZ, UK.

1. Hofmann, D.J. \& Solomon, S. J. geophys. Res. 94 5029-5041 (1989).

2. Molina, M.J., Tso, T.L., Molina, L.T. \& Wang, F.C Science 238, 1253-1259 (1987).

3. Tolbert, M.A., Rossi, M.J. \& Golden, D.M. Geophys. Res. Lett. 15, 851-854 (1988).

4. Leu, M.T. Geophys. Res. Lett 15, 17-20 (1988).

5. Solomon, S., Mount, G.H., Sanders, R.W. \& Schmeltekopf, A.L. J. geophys. Res 92,8329 (1987).

6. Fahey, D.W. et al. J. geophys. Res. (in the press).

7. Brune, W.H., Anderson, J.G. \& Chan, K.R. J. geophys Res. (in the press)

8. Toon, O.B., Hammill, P., Turco, R.P. \& Pinto, J. Geophys. Res. Lett. 13, 1284 (1986)

9. Jones, R.L. et al. J. geophys. Res (in the press)

10. Anderson, J.G. et al. J. geophys. Res. (in the press)

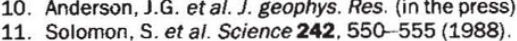

12. Junge, C.E., Chagnon, C.W. \& Manson, J.E. J. Meteorol. 18, 81-108 (1961).

13. Turco, R.P., Whitten, R.C. \& Toon, O.B. Rev. Geophys. Space Phys. 20, 233 (1982)

14. Krueger, A.J. Science 220, 1377-1379 (1983).

15. Thomas, G.E., Jakosky, R.A., West, R.A. \& Sanders, R.W. Geophys. Res. Lett. 10, 997 (1983).

16. Reiter, R., Jager, H., Carnuth, W. \& Funk, W. Geophys. Res. Lett. 10, 1001 (1983)

17. Rodriguez, J.M., Ko, M.K.W. \& Sze, N.D. Geophys. Res. Lett. 15, 257-260 (1987).

\section{The fabric of life}

LAST week Daedalus presented 'Livewear', a novel form of clothing in which an inert base-fabric supports a fibrous mat of selfrenewing moss or similar vegetation. Moistened by the constant slight sweating of human skin, and absorbing dirt and grime as a fertilizer, it cleans and repairs itself, and even grows, in normal use.

Daedalus is now seeking to extend this principle to other fabrics. Living wash flannels, napkins and tablecloths would doubtless pick up enough water and nutrients in normal careless domestic use; but biological carpets, curtains and so on would wilt and die from lack of moisture. But Daedalus recalls the Lomas vegetation of Peru, which draws moisture out of the air and can grow in regions where rain never fails. Some plants can work this trick even in quite unsaturated air.

So DREADCO's biologists are playing the usual breeding and mutation games: crossing promising varieties with each other, exposing them to strong ionizing radiation, and so on. They hope to develop a plant variety or stable ecosystem which not only forms a coherent fibrous growth on a base fabric, but extracts enough water from the air to survive on its own.

The new 'Phytomat' will have many uses. As a domestic fabric in rugs and curtains and bedding, and so on, it will give the house a delightful natural look. It will never need renewing or cleaning; and it will keep the rest of the house clean as well, by absorbing and metabolizing household dust and dirt (which is mainly organic). One problem may be its tendency to spread. Even the smallest Phytomat rug in a room might in time colonize the whole room, covering floor, walls, ceiling and furniture with a soft, verdant, insulating living layer. Even the occupants themselves, or at least their clothing, could be at risk. The DREADCO team may have to restrict the seeding cycle of their new product, or devise a special herbicidal coating to keep it in bounds.

On the other hand, a self-spreading mossy vegetable mat could be a wonderful land reclamation system. A big roll of a suitable Phytomat fabric could simply be spread over some dusty patch of wasteland and left. Absorbing moisture from the air and nutrients from the soil, it would soon establish itself as a primary ecosystem, ultimately to be built on and replaced by the richer and more varied ecosystem natural to the area. Dustbowls could be reclaimed and deserts colonized. Daedalus even has plans for a special Phytomat garden for lazy householders, 'printed' in tasteful patterns with the seeds of grasses, shrubs and flowers. Just roll it out over your neglected yard, and in due course a perfect garden will arise, the envy of the neighbours.

David Jones 